Georgia State University

ScholarWorks @ Georgia State University

1995

\title{
The Roepke Lecture in Economic Geography Catastrophic Earthquake Insurance: Patterns of Adoption
}

Risa Palm

Georgia State University, risapalm@gsu.edu

Follow this and additional works at: https://scholarworks.gsu.edu/geosciences_facpub

Part of the Geography Commons, and the Geology Commons

\section{Recommended Citation}

Palm, Risa, "The Roepke Lecture in Economic Geography Catastrophic Earthquake Insurance: Patterns of Adoption" (1995). Geosciences Faculty Publications. 9.

https://scholarworks.gsu.edu/geosciences_facpub/9

This Article is brought to you for free and open access by the Department of Geosciences at ScholarWorks @ Georgia State University. It has been accepted for inclusion in Geosciences Faculty Publications by an authorized administrator of ScholarWorks @ Georgia State University. For more information, please contact scholarworks@gsu.edu. 


\title{
The Roepke Lecture in Economic Geography ${ }^{\mathrm{i}}$ Catastrophic Earthquake Insurance: Patterns of Adoption
}

\begin{abstract}
The surveys yielded three primary findings. First, the proportion of households subscribing to earthquake insurance increased steadily, from about 5 percent in 1973 to approximately 40 percent in Santa Clara and Los Angeles counties in 1989 and 50 percent in those counties in 1993. Second, the geographic pattern of insurance subscription has consistently been unrelated to relative geophysical risk: those in areas susceptible to high degrees of ground shaking are no more likely to purchase insurance than those in less risky areas. Third, the strongest and most consistent predictor of earthquake insurance purchase is perceived vulnerability: those who perceive that their homes or communities are likely to experience earthquake damage are more likely to purchase earthquake insurance. Future research should involve cross-cultural studies, specifically addressed at questions of the universality of the empirical relationships between personality, demographic-economic status, and insurance purchase, or, more broadly, earthquake-mitigation behavior.
\end{abstract}

Key words: earthquake hazards, environmental perception, insurance.

A magnitude 7.2 earthquake on 17 January 1995 near Kobe, Japan reminded us of the power of this natural hazard to claim lives and damage property. More than 5,000 persons lost their lives, more than 350,000 were made homeless, and estimates of property damage exceed $\$ 100$ billion. This earthquake occurred on the first anniversary of the magnitude 6.6 Northridge, California earthquake of 17 January 1994. The 1994 earthquake claimed 60 lives, and 15,000 were made homeless (EERI 1994). It was the most destructive earthquake within the United States since the 1906 San Francisco earthquake, with damage estimates over \$20 billion. Of course, an even more serious threat is the potential "great earthquake" of magnitude 8.3 predicted for the San Andreas fault or magnitude 7.5 on the Newport-Inglewood fault near downtown Los Angeles. Depending on the time of day, either earthquake could cause many thousands of deaths and direct economic losses in excess of $\$ 70$ billion (FEMA 1980; Earthquake Project 1989).

Tales of families that had lost their homes appeared in newspapers and magazines following the January earthquake (Fuerbringer 1994; Liedtke 1994; Kenner 1994; Murr 1994; Van Biema 1994). Although government loans were avail- able, the economic losses of such families will, in many cases, completely wipe out personal savings and perhaps cause other, collateral personal disruptions to their lives. 
Although earthquake insurance cannot prevent the collapse of buildings or reduce the loss of life, it can reduce the negative impact of an earthquake on the household. Furthermore, spatial variability in the adoption of earthquake insurance is an important topic for geographic study; it not only reveals patterns of society-environment interaction but also identifies the spatial variation of populations more or less at risk from severe personal economic losses following a major damaging earthquake.

\section{The Geography of Earthquake Hazard Mitigation}

The way in which societies and individuals evaluate hazards in the environment and the way in which they turn these evaluations into selected behaviors reveals much about their values as well as the functioning of society. In the case of earthquake hazards, individuals, communities, and society at large must cope with dangers-known, anticipated, and unknown-in the geophysical environment.

Seismologists are still unable to predict earthquakes within a time frame that is useful for emergency management and planning. Such "operative predictions" (Alexander 1993) would require information on the location of the event, the area most likely to be affected, a relatively short time interval (no more than several days) in which the event is likely to occur, and the magnitude of the event. Prediction at this level of spatial and temporal specificity continues to elude science (Alexander 1993; National Research Council1976; Bolt 1993). Furthermore, as the January 1994 Northridge earthquake demonstrated, not all potential earthquake sources are now known.

However, given current knowledge from seismology about the distribution of earthquake risk, past earthquake events, seismic gaps, and estimated recurrence intervals, combined with an understanding about the behavior of certain classes of soil and rock under conditions of ground shaking, we should be able to plan land use in response to known hazards (Bolt 1993). Areas known to be susceptible to liquefaction within regions of known seismic risk can be zoned in such a way as to prevent large-scale concentration of human habitation.

The application of construction science-the way in which certain types of building design and construction can minimize damage or failure-can also affect vulnerability (Cere and Shah 1984). States and local jurisdictions can pass construction standards to ensure that building practice takes knowledge of earthquake resistance into account. States like California have led the way in mandating increasingly stricter construction standards, although loopholes for "small projects" (single-family homes) or laxity in insisting on retrofitting existing buildings places many at risk (Alesch and Petak 1986).

Individuals can also take measures to protect themselves against some of the worst effects of an earthquake in the first 72-hour emergency period. Public information about earthquake hazards and potential mitigation measures is available from a large and growing number of sources. 
Teacher training programs have introduced earthquake-mitigation units into the public schools (Thier 1988). Scout organizations have earthquake-mitigation badges. Local governments have sponsored earthquake awareness days (Mat- tingly 1987). Telephone books contain information on emergency procedures to follow during and immediately after an earthquake. Real estate agents must present to purchasers of pre-1960 homes copies of "The Homeowner's Guide to Earthquake Safety," a booklet containing information on geologic and seismic hazards, explanations of structural and non-structural earthquake hazards, and recommendations for mitigating the hazards (Business and Professions Code, Art. 1, Chap. 3, Sees. 10130-10149). The United States Geological Survey, the Office of the State Geologist, the Federal Emergency Management Agency, Southern California Earthquake Preparedness Project, Bay Area Regional Earthquake Preparedness Project, and other organizations have developed and distributed brochures, maps, scientific reports, and other materials on the earthquake hazard and measures that can be adopted to mitigate some of its effects. In short, public information about the earthquake hazard and recommended steps to prepare for an earthquake has been widespread (Mileti and Fitzpatrick 1993).

A great deal of effort and attention has been focused on understanding seismic risk and providing information to people about appropriate response. The focus of this paper is one specific lens through which to view the response of individuals and households to earthquake hazard- that is, the decision to purchase earth- quake insurance. The decision to purchase insurance is one of the classic ways in which economists have measured the ways in which individuals make decisions in an uncertain environment (Friedman and Savage 1948; Edwards 1955; Mosteller and Nogee 1941; Kunreuther et al. 1978). For geographers, the earthquake insurance decision process not only illuminates individual risk-taking but also reflects more generally on individual as well as societal response to a risky geophysical setting.

Earthquake Insurance

Why purchase insurance? Why not rely on government aid after the earthquake? The answer is that the normal homeowner's insurance (fire insurance) policy will cover smoke damage associated with an earthquake-related fire but will not cover damage to the structure due to the earth movement itself (Brown and Gerhart 1989). The federal government will not provide grants; the Federal Emergency Management Agency (FEMA) will provide lodging for up to 18 months and may provide loans of up to $\$ 100,000$ to repair the house or rebuild, as well as tax relief (Earthquake Project 1989). Thus, without insurance the homeowner will be repaying both the government loan as well as the original mortgage loan.

Earthquake insurance is available within the United States as an addendum to the homeowner's insurance policy that is usually required as a condition for a mortgage loan. California state law mandates that insurance companies offer earthquake insurance to homeowner's insurance holders ( $\$ 1081$, Sec. 2 of Stats. 1984, c. 916. California Insurance Code). This additional insurance, however, is not mandatory except in Puerto Rico (Palm and Hodgson 1992). 
The cost of earthquake insurance varies from state to state. In California, in those counties particularly susceptible to earth- quake damage (along the San Andreas fault, for example), earthquake insurance premiums range from $\$ 2.00$ to $\$ 2.50$ per $\$ 1,000$ of coverage with a 5 to 10 percent deductible (Roth 1990). In California, therefore, the cost for coverage of a $\$ 300,000$ home (excluding the value of the land) would be $\$ 600$ to $\$ 750$ per year. Do Californians adopt earthquake insurance? This is the question that a series of surveys attempted to address.

\section{Study Design}

In order to assess the response of owner-occupiers in California to the earthquake hazard and the earthquake insurance purchase decision, four study areas were selected to represent both urban and suburban counties in both northern and southern California areas that varied in objective geophysical risk, at least insofar as that is represented by the pattern of past earthquake events (Fig. 1).

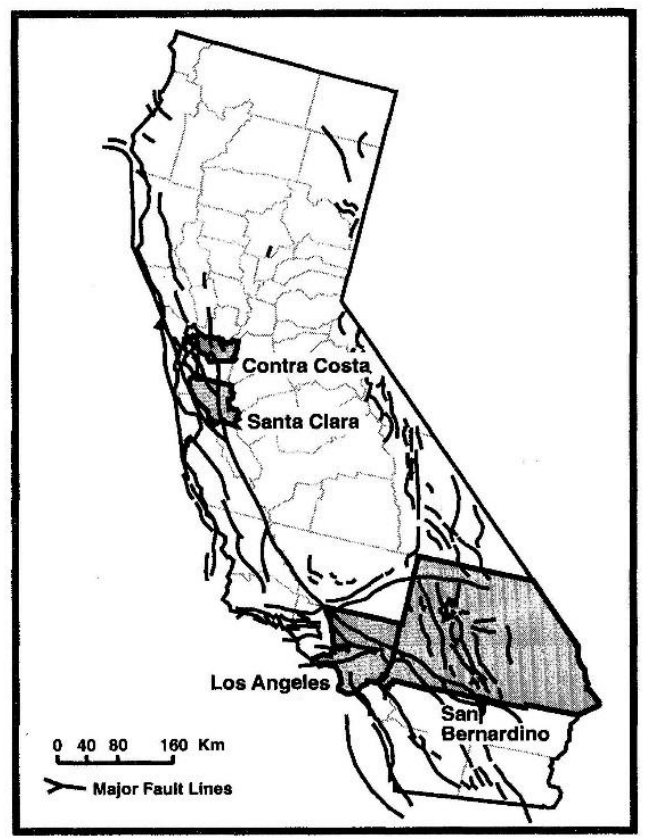

Figure 1. California study areas. The four survey counties and special studies zones are highlighted.

The four study counties were Contra Costa, a largely suburban county in the east bay of the San Francisco region transected by the Concord and Calaveras faults; Santa Clara, with its urban center of San Jose and generally upper-middle- class suburbs, including Los Gatos, Sunnyvale, Mountain View, and Palo Alto, and including both the San Andreas and Hayward faults within its boundaries; Los Angeles, including a diverse population of owner-occupiers and crossed by numerous faults, including the Inglewood, San Fernando, San Gabriel, and San Andreas faults; and San Bernardino, a diverse county including city centers, suburban and retirement communities, as well as rural settlement, with a fairly large Latino population, and particularly vulnerable in that southern portions of the San Andreas fault transect some densely populated portions of the county. 
The study was limited to owner- occupiers. Condominium dwellers were excluded from this sample because insurance decisions of a collectivity as large as a homeowners' association involve group interactions that elude a simple analysis of individual characteristics and risk perceptions. Similarly, renters were not included since the decision to insure the structure against earthquake damage is not usually made by the tenant.

The list of owner-occupiers sampled was that kept by the county tax assessor's office. This record contains names and addresses for all properties on the tax roll in each county and is updated each year for property improvements and transactions. A random sample of approximately 1,000 names was drawn for each county. The actual population surveyed was limited to those approximately 3,150 addresses that could also be geocoded.

The total design method (Dillman 1978) was used to design and execute the mail survey. The questionnaire booklet and cover letters were designed according to the advice Dillman provides on mail survey research. Further, the sequence of mailings involved four steps: (1) the initial mailing of the cover letter and questionnaire; (2) several days later, a postcard thanking respondents and reminding nonrespondents to return questionnaires; (3) 21 days after the initial mailing, a letter and replacement questionnaire to nonrespondents; and (4) 49 days after the initial mailing, a letter and replacement questionnaire sent to nonrespondents by certified mail. In addition, where telephone numbers were available, a telephone contact was made with the respondent instead of the third mailing. Each step increases the cumulative response rate.

\section{Survey Timing}

The series of three surveys of California homeowners was not originally designed as a longitudinal study. Instead, the 1989 study was intended as a one-time, cross- sectional survey designed to update an earlier, definitive study of earthquake insurance subscription undertaken in 1973-74 (Kunreuther et al. 1978). The 1970s study had found that only 5 percent of California residents were insured against earthquake damage, but that study had not investigated the spatial and demographic correlates of insurance subscription. Subsequent earthquakes, as well as insurance disclosure legislation passed in the interim, led us to expect that the rate of insurance adoption had increased substantially. The first survey was completed during the spring and summer of 1989 (Fig. 2). 


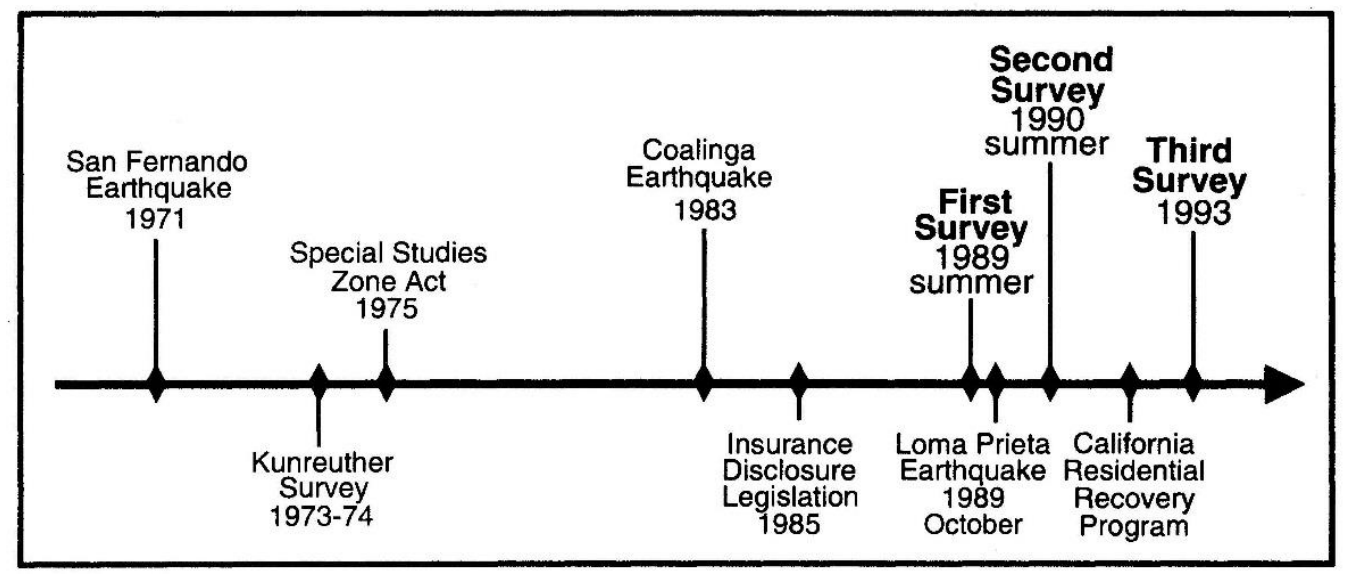

Figure 2. Timing of the three surveys

The second survey was conducted in the summer of 1990. This survey was triggered by the Lorna Prieta earthquake of 17 October 1989. This magnitude 7.1 earth- quake was one of the strongest in California since 1906. Buildings were damaged in San Francisco, Marin, Alameda, San Mateo, Santa Cruz, and Santa Clara counties. Two of the counties in the 1989 survey suffered direct impacts of this earthquake. Santa Clara County had \$728 million in direct damage to buildings, including 5,124 homes damaged and 131 destroyed (Mc- Nutt and Sydnor 1990). Contra Costa County suffered less damage, with losses of $\$ 25$ million in property, but residents accustomed to using the Bay Bridge in their commute to San Francisco were inconvenienced by its closure. The varying levels of experience with an earthquake in the four study counties made the recently surveyed population an unusual natural field design to test for the impacts of experience with an earthquake on the insurance purchase decision, changes in perceived risk, and the adoption of noninsurance mitigation measures.

The third survey was conducted in early 1993. The impetus for this survey was the passage in 1990 of a mandatory quasi-insurance program that would cover small losses (up to $\$ 15,000$ ) with a very low deductible (California Insurance Code, Chap. 4.5, Sec. 5009). This pro- gram, the California Residential Earth- quake Recovery Fund, was in effect only during the 1992 calendar year. It was hypothesized that the existence of the new insurance requirement might in- crease subscription to catastrophic earth- quake insurance, since public attention would be focused on the need for such coverage.

\section{Sampling and Response Rate}

The original survey in 1989 was sent to 864 households in Contra Costa County, 855 in Santa 
Clara County, 743 in Los Angeles County, and 683 in San Bernardino County, or a total of 3,145 house- holds. The original mailing list contained a large number of errors-addresses that did not exist or individuals who had moved leaving no forwarding address. Only 1,786 completed surveys were mailed back (or approximately 57 percent of the total names and addresses drawn), of which 1,512 (48 percent of the total) contained valid responses.

The 1990 survey was mailed to the same name/address of the household used in the 1989 survey. We did not request that the same individual fill out the questionnaire in 1990 as in 1989. Of the 1,512 questionnaires mailed in the 1990 survey, 1,071 were returned with a valid response ( 71 percent of the total mailed, or 34 percent of the original list).

The 1993 survey list was enlarged to the 1989 base by adding the names of households occupying the 1989 survey sites-that is, if in 1993 a new owner- occupier was listed for a dwelling surveyed in 1989, we mailed a survey to this individual. The 1993 survey was mailed to 2,256 owner-occupiers for single-family dwellings in the four counties, netting a total valid response of 1,329 (58.9 per- cent). The three surveys were analyzed as cross-sectional samples.

In addition, the 1993 survey asked respondents to indicate whether they had personally responded to a similar survey "from us in 1989" and "again in 1990." For those who responded yes to both questions, we did a separate analysis of longitudinal changes in perception and behavior in the same individuals. This very small group (a total of just 149 households) can be considered a "panel," but is certainly not representative of the owner-occupiers in the source counties.

\section{Hypothesis Testing}

The three surveys tested six hypotheses based on theoretical work as well as on other empirical studies. The first survey tested four hypotheses: (1) that rates of earthquake insurance purchase had risen during the 1974-89 period, partly as a result of increased public information about earthquake hazards and the avail- ability of insurance as a remedy (Brown and Gerhart 1989; Kunreuther et al. 1978); (2) that a series of socioeconomic and demographic characteristics were systematically related to the insurance purchase decision-for example, that those with more to lose (with relatively higher net equity in the property) as well as those with a shorter earning future (the elderly) are more likely to purchase earthquake insurance (Anderson and Weinrobe 1981; Schiff 1977; Cutter, Tiefenbacher, and Solecki 1994; Drabek 1986; Willinger 1989; Kunreuther et al. 1978; Turner et al. 1979; Hodge, Sharp, and Marts 1979); (3) that insurance purchase was systematically related to localized variability in geophysical risk-for example, those located in special studies zones or close to an active surface fault trace would be more likely to purchase earthquake insurance (Stewart Economics 1989); and (4) that quite apart from actual geophysical risk, perceived risk was a major predictor of insurance purchase (White and Haas 1975; Drabek 1986; Turner et al. 1979; Slovic, Fischhoff, and Lichtenstein 1980).

The post-Lorna Prieta survey in 1990 added a fifth hypothesis addressing the impacts of 
experience with the earth- quake on both hazard perception and response. This survey tested the hypothesis that direct experience with the hazard or proximity to houses that had been damaged by the earthquake would in- crease both perceived vulnerability and the adoption of mitigation measures. This hypothesis is based on a great deal of previous empirical and theoretical work linking experience and subsequent response (Kunreuther et al. 1978; Kunreuther and Kleffner 1991; Laska 1986; Burby et al. 1988; Kates 1971; Burton and Kates 1964; Roder 1961; Saarinen 1982; Greene, Perry, and Lindell 1981; Wein- stein 1989; Kahneman and Tversky 1979; Perloff 1983; Slovic, Kunreuther, and White 1974; Janis 1967; Averill1987).

The 1993 survey tested a sixth hypothesis concerning the impact of the mandatory insurance program on the voluntary purchase of catastrophic insurance. This hypothesis stated that the California Residential Earthquake Recovery Fund Program would induce previously uninsured house- holds to purchase catastrophic earthquake insurance. The theoretical basis of this hypothesis rests on "framing theory" (Lichtenstein and Slovic 1971; Goldstein and Einhorn 1987; Johnson, Payne, and Bettman 1988; Schkade and Johnson 1989). Framing theory says that a shift in the framing of the risk (in this case, a new state policy that mandates earthquake coverage) induces a shift in consumer perception of this environmental risk, increasing perceived vulnerability and in this case inducing purchase of catastrophic insurance.

\section{Survey Findings}

The three surveys showed consistent patterns of earthquake hazard response and insurance adoption, whether among the cross-sectional respondents or the longitudinal respondents (those who stated that they had responded to all three surveys). An analysis of the cross- sectional respondents is presented here. 1

Insurance Subscription. The 1973-74 survey by Kunreuther et al. (1978) had found only 5 percent of California home- owners with earthquake insurance. Not only were the percentages insured far greater during the beginning of the study period, but also during the period from 1989 to 1993 rates of earthquake insurance subscription climbed steadily in each of the study counties (Table 1). By early 1993, more than 50 percent of the respondents in Santa Clara and Los Angeles counties claimed to have earth- quake insurance. A large number of households, a majority in San Bernardino and Contra Costa counties, remain uninsured, however.

Relationship of Socioeconomic and Demographic Variables. Logistic regression equations were calculated to test the strength of associations between the dependent variable (does or does not have earthquake insurance) and a set of independent variables measuring economic and

\footnotetext{
${ }^{1}$ More detail about the methodology and findings of the three surveys are available for 1989 (Palm et al. 1990), 1990 (Palm and Hodgson 1992), and 1993 (Palm 1995).
} 
demographic characteristics such as length of residence in California, place of birth, age, gender, ethnicity, school years completed, presence of persons over age 65 in household, presence of children under age 18 in household, home value, equity in the home, and family income. In addition, individual variables were tested for the strength of their association with insurance status. No consistent relationships between socioeconomic or demographic variables and insurance status were found across all four counties; for example, in- come was related to insurance status in Contra Costa County and San Bernardino County in 1993 but not in 1989, nor were these two factors related in the two other study counties in either 1989 or 1993. Similarly, age of the homeowner was related to insurance status in Contra Costa County in 1993 but not in 1989, in Los Angeles County in 1989 but not in 1993, and in no other county in either year.

Table 1. Percentage of Households with Earthquake Insurance

\begin{tabular}{|l|l|l|l|}
\hline County & $\mathbf{1 9 8 9}$ & $\mathbf{1 9 9 0}$ & $\mathbf{1 9 9 3}$ \\
\hline Contra Costa & 22.4 & 29.3 & 36.6 \\
\hline Santa Clara & 40.4 & 50.8 & 54.0 \\
\hline Los Angeles & 39.6 & 45.8 & 51.6 \\
\hline San Bernardino & 29.2 & 34.6 & 42.6 \\
\hline
\end{tabular}

Geophysical Risk and Insurance. The surveys clearly showed that geophysical risk is consistently unrelated to the adoption of earthquake insurance. Geophysical risk was represented by distance from an active fault trace, distance from the San Andreas fault, location within a special studies zone (designed surface fault trace zone), or potential ground- shaking classification zone (Evernden and Thomson 1985). Whether analyzed as individual variables or in combination with other variables, geophysical risk was unrelated to the adoption of earthquake insurance in all of the counties in each of the three survey years.

Perceived Risk and Insurance. In contrast to objective risk, perceived risk was a major predictor of earthquake insurance purchase. Respondents in all three surveys were asked to estimate the probability of a major earthquake damaging their community or their home. These questions consistently discriminated the insured from the uninsured. Those with higher perceived vulnerability to future earthquakes are more likely to adopt earthquake insurance than those who believe that an earthquake is unlikely to affect their home or their community. For example, in the logistic regressions for 1989 and 1993, perceived risk variables were included in the model that classified the insured and the uninsured in both study years and in each study county. Perceived risk was the most important and most consistently related variable predicting insurance purchase.

Experience with an Earthquake. The Lorna Prieta earthquake affected primarily Santa Clara County and, to a lesser extent, Contra Costa County. We observed major differences in responses to the 1989 and 1990 survey questions in these counties. For example, in 1989 about 34 percent of the uninsured respondents in both counties felt that earthquake insurance was unnecessary. By 
1990 only about 5 percent in these counties gave this response. In 1989 about 35 percent felt that a major earthquake was likely to affect their own home in the next ten years; by 1990 this number had increased to about 41 percent in Contra Costa County and 53 percent in Santa Clara County. These shifts in perceived vulnerability were even more dramatic among the insured households: in 1989, 59 percent of the insured households in Santa Clara County and 44 percent in Contra Costa County stated that they felt an earthquake was likely or very likely to affect their homes. By 1990 these percentages had increased to 73 percent and 59 percent respectively. Finally, the largest in- crease in percentage insured in this period occurred in Santa Clara County, where 11 percent of the households adopted insurance between 1989 and 1990.

Another way of measuring the impacts of earthquake experience on insurance purchase was the use of responses to questions such as "was there damage to your house in the 1989 earthquake?"; "has the house ever suffered damage from an earthquake?"; and "do you personally know someone who has had property damage from an earthquake?" These variables were inconsistent in predicting insurance purchase; the 1993 logistic regression equations showed a relationship with prior earthquake experience for Contra Costa and Los Angeles counties, but not for Santa Clara or San Bernardino counties.

Experience with an earthquake seems to have a differential effect on the subsequent adoption of earthquake insurance. Perceived vulnerability seems to increase, at least over the short run, following an earthquake.

Mandatory Insurance. The 1993 survey tested the impacts of the California Residential Earthquake Recovery Fund program, as well as confidence in the insurance industry, on the decision to purchase insurance. When asked to rate various factors as important or unimportant in the purchase decision, insured respondents indicated that the California Residential Earthquake Recovery Fund was "very unimportant" in the decision, while relative confidence in the insurance industry was an important factor. Similarly, those who chose not to purchase insurance were not affected by the existence of this fund, but their lack of confidence that the -insurance industry would actually pay out benefits in a major disaster was an important factor. Thus, the existence of the recovery fund made little difference in whether or not homeowners purchased catastrophic earthquake insurance.

Summary of Findings. In sum, the percentage of homeowners purchasing earthquake insurance has increased steadily, although a large proportion of California homeowners continue to be uninsured. Although experience with an earthquake seems to have some effect on insurance purchase, the major factor affecting insurance purchase is perceived risk. Insurance purchase is not consistently related to socioeconomic or demographic characteristics and is unrelated to relative geophysical risk within the metropolitan area. 


\section{Future Directions of Research}

These findings reinforce other findings on the impacts of risk perception on mitigative behavior. There is reason to doubt their universality, however. The first suggestion that such work might be culturally specific came from a parallel study in Puerto Rico, looking at hurricane as well as earthquake hazards (Palm and Hodgson 1993). In response to the same risk vulnerability questions, Puerto Rican homeowners indicated a greater level of concern with earthquakes than with hurricanes; further- more, when responding to the same questions, they showed more concern about earthquake damage than did the Californians. This is particularly remarkable when one considers that the last major earthquake occurred in Puerto Rico in 1918, killing an estimated 116 people in the ensuing tsunami, with about $\$ 4$ million damage (in current dollars) to property. This event, hardly the most salient risk facing Puerto Ricans, should not have triggered the strength of response noted in the survey. Although perceived vulnerability was also the key predictor of hazard mitigation in Puerto Rico, there was reason to believe that cultural differences even between these two regions-California and Puerto Rico-had a serious impact on research findings.

Researchers within the United States have enumerated decision-making "errors," the importance of risk communication, the importance of "framing" in affecting public response, and the difficulties of assessing an appropriate response to low- probability events. Three examples are the "gambler's fallacy," "editing," and "anchoring and adjustment." The gambler's fallacy is the belief that if a low-probability event has occurred recently, then it is unlikely to occur again soon and therefore can be treated as a zero-probability event (Slovic, Kunreuther, and White 1974). A second error is known as "editing," which occurs when individuals dismiss the risk of loss when the probability falls below a given level (Kahneman and Tversky 1979; Slovic et al. 1977). A third error has been termed "anchoring and adjustment," which refers to a tendency to estimate the loss or gain at a particular level and then intuitively adjust estimations over time around this first approximation (Tversky and Kahneman 1974; Einhorn and Hogarth 1985). Such theory on risk perception and its linkage to subsequent behavior has been primarily validated with empirical studies of a single population: Western, middle class, and largely white. Therefore, the empirical basis for the current theories of risk perception may be unnecessarily narrow.

Some have argued that cultures vary in the basic premise about what constitutes the "self." On the one hand, it is said that many Western cultures have a strong belief in separateness, independence, or autonomy of each distinct self (Bellah et al. 1985). Social relationships are important in these cultures, but they typically take the form of voluntary transaction of otherwise separate individuals. An emerging cultural psychology literature (Berman 1990; Markus and Kitayama 1992; Shweder 1991; Shweder and LeVine 1984; Stigler, Shweder, and Herdt 1991) suggests that theories of decision making and risk perception based on the notion of personal utility or benefit/cost analysis may be most valid among those who share the attendant assumption about the self as independent and about social behavior as voluntary. Cultures that emphasize this independent construal will also likely show strong empirical relationships 
between in- dependent assessment of risk and subsequent behavior. These are precisely the empirical relationships found in the reported studies in California and Puerto Rico.

On the other hand, many non-Western cultures, especially Asian ones, are said to emphasize a belief in the inherent connectedness of individuals making up a coherent in-group. In these cultures "self" is viewed as interconnected with other selves within a variety of socially meaningful contexts (e.g., "me at home," "me as a teacher in school," and so forth). This second, more relationship-oriented view of self may be referred to as "interdependent construal" (Kitayama and Markus 1993). In cultures with the relationship- oriented view of self, riskmitigation behavior may be more related to socially shared rules or norms than to individuallevel assessments.

A related example of the significance of cultural psychology to the study of environmental risk perception is research on "illusory optimism." A number of studies have suggested that Americans estimate that they live longer than other people, that they are younger for their age than others, and that they are less likely to die from cardiovascular diseases or accidents of many different kinds (Kitayama and Markus 1993; Weinstein 1987). This is the type of generalization that Garrison Keillor notes (in his National Public Radio show, "A Prairie Home Companion”) when he says that all residents of Lake Wobegon are "above average." Research has found an absence of this optimistic bias in self-perception among Japanese college students (Markus and Kitayama 1991; Heine and Lehman 1992). This cultural difference in degree of optimism about personal well-being could also affect perceived vulnerability and the propensity to take riskmitigation actions. Some initial forays into the identification of subcultural differences in ethnic/ racial group assessment of hazards have already been completed (Perry, Greene, and Mushkatel 1986; Turner, Nigg, and Paz 1986). Findings of subcultural variability in response within United States society suggest the need for careful cross-cultural research to determine the extent to which generalizations about hazard perception and response can be taken as universal or are limited by cultural, economic, or political context.

Not all of the potential sources for cultural contrasts in response to natural hazards are enumerated here, of course. But this review may be enough to suggest that this is a rich field-one that needs to be investigated if we are to be more confident of our understanding of human response to risks in the natural environment. Cross-cultural study should shed light on the issue of the universality of the empirical relationships between personality, demographic-economic status, and insurance purchase, or, more broadly, earthquake-mitigation behavior.

\section{Afterword}

Many tragic events cause deaths, disrupt the lives of survivors, and cause damage to property. Some of these events are unanticipated and therefore mitigation measures cannot be taken; earthquakes are not among this class of hazards. The susceptibility of large populations within California to earthquake-related damage and destruction is well known. California residents are 
aware of the earthquake risk. Many federal and state programs have been undertaken to prepare for a major earthquake and to minimize the loss of life and property. Yet many households do little to protect themselves from this environmental hazard. A significant question is whether or not the population at risk can be aroused to take mitigative measures before the "great" earthquake that looms in the not-too-distant future occurs.

\section{References}

Alesch, D. J., and Petak, W. J. 1986. The politics and economics of earthquake hazard mitigation. Program in Environment and Behavior, Monograph No. 43. Boulder: University of Colorado, Institute of Behavioral Science.

Alexander, D. 1993. Natural disasters. New York: Chapman and Hall.

Anderson, D., and Weinrobe, M. 1981. Geographic mortgage risk: Implications for the Federal Home Loan Mortgage Corporation. Washington, D.C.: Kaplan, Smith \& Associates.

Averill, J.R. 1987. The role of emotions and psychological defense in self-protective behavior. In Taking care: Understanding and encouraging self-protective behavior, ed. N. D. Weinstein, 54-78. New York: Cambridge University Press.

Bellah, R. N.; Madsen, R.; Sullivan, W. M.; Swidler, A.; and Tipton, S. M. 1985. Habits of the heart: Individualism and commitment in American life. Berkeley: University of California Press.

Berman, J. J. 1990. Cross-cultural perspectives: Nebraska symposium on motivation. Lincoln: University of Nebraska Press.

Bolt, B. 1993. Earthquakes. New York: W. H. Freeman.

Brown, J. M., and Gerhart, P. 1989. Utilization of the mortgage finance and insurance industries to induce the private procurement of earthquake insurance: Possible antitrust implications. Working Paper No. 66. Boulder: University of Colorado, Institute of Behavioral Science.

Burby, R. J.; Bollens, S. A.; Holloway, J. M.; Kaiser, E.; Mullan, D.; and Sheaffer, J. R. 1988. Cities under water. Program in Environment and Behavior, Monograph No. 47. Boulder: University of Colorado, Institute of Behavioral Science.

Burton, I., and Kates, R. W. 1964. The perception of natural hazards in resource management. Natural Resources Journal 3:412-41.

Cutter, S. L.; Tiefenbacher, J.; and Solecki, W. D. 1994. Engendered fears: Femininity and technological risk perception. In Environmental risks and hazards, ed. S. Cutter, 13749. Englewood Cliffs, N.J.: Prentice- Hall.

Dillman, D. 1978. Mail and telephone surveys: The total design method. New York: Wiley. Drabek, T. 1986. Human system responses to disaster: An inventory of sociological findings. New York: Springer-Verlag.

Earthquake Engineering Research Institute (EERI). 1994. Technical briefings on the Southern California earthquake of January 17, 1994. Oakland: EERI, February.

Earthquake Project of the National Committee on Property Insurance. 1989. Catastrophic earthquakes: The need to insure against economic disaster. Boston: National Committee on Property Insurance.

Edwards, W. 1955. The prediction of decisions among bets. Journal of Experimental 
Psychology 50:201-14.

Einhorn, H., and Hogarth, R. 1985. Ambiguity and uncertainty in probabilistic inference. Psychological Review 92:433-61.

Evernden, J.F., and Thomson, J. M. 1985. Predicting seismic intensities. In Evaluating earthquake hazards in the Los Angeles region: An earth-science perspective, ed. J. I. Ziony, 151-202. Professional Paper 1360. Reston, Va.: U.S. Geological Survey.

Federal Emergency Management Agency (FEMA). 1980. An assessment of the consequences and preparations for a catastrophic California earthquake: Findings and actions taken. Washington, D.C.: FEMA.

Friedman, M., and Savage, L. J. 1948. The utility analysis of choices involving risk. Journal of Political Economy 56:279-304.

Fuerbringer, J. 1994. Waking in astonishment to see a street destroyed. New York Times, 18 January, A17.

Cere, J. M., and Shah, H. C. 1984. Terra non firma: Understanding and preparing for earthquakes. Stanford, Calif.: Stanford Alumni Association.

Goldstein, W. M., and Einhorn, H. J. 1987. Expression theory and the preference reversal phenomena. Psychological Review 94: 236--54.

Greene, M.; Perry, R.; and Lindell, M. 1981. The March 1980 eruptions of Mt. St. Helens: Citizen perceptions of volcano threat. Disasters 5(1):49--66.

Heine, S., and Lehman, D. 1992. A cross-cultural study of positive illusions. Typescript. University of British Columbia.

Hodge, D.; Sharp, V.; and Marts, M. 1979. Contemporary responses to volcanism: Case studies from the Cascades and Hawaii. In Volcanic activity and human ecology, ed. P. D. Sheets and D. K. Grayson, 221-48. New York: Academic Press.

Janis, I. L. 1967. Effect of fear arousal on attitude change: Recent developments in theory and experimental research. In Advances in experimental social psychology, ed. L. Berkowitz, 166-224. New York: Academic Press.

Johnson, E. J.; Payne, J. W.; and Bettman, J. R. 1988. Information displays and preference reversals. Organizational Behavior and Human Decision Processes 42:1-21.

Kahneman, D., and Tversky, A. 1979. Prospect theory: An analysis of decision under risk. Econometrica 47(2):263-91.

Kates, R. W. 1971. Natural hazard in human ecological perspective: Hypotheses and models. Economic Geography 47:438-51.

Kenner, L. 1994. Losses: Not having insurance takes a toll. The Outlook, 19 January, C-9.

Kitayama, S., and Markus, H. R. 1993. A cultural perspective to self-conscious emotions. In Shame, guilt, embarrassment, and pride: Empirical studies of self-conscious emotions, ed. J. P. Tangney and K. W. Fisher. New York: Guilford.

Kunreuther, H.; Ginsberg, R.; Miller, L; Sagi, P.; Slovic, P.; Borkan, B.; and Katz, N. 1978. Disaster insurance protection: Public policy lessons. New York: John Wiley and Sons.

Kunreuther, H., and Kleffner, A. E. 1991. Should earthquake mitigation measures be voluntary or required? Working Paper no. 91-04-01. Philadelphia: Wharton School, University of Pennsylvania, Risk and Decision Process Center.

Laska, S. B. 1986. Involving homeowners in flood mitigation. Journal of the American Planning Association 52:452-66.

Lichtenstein, S., and Slovic, P. 1971. Reversals of preference between bids and choices in gambling decisions. Journal of Experimental Psychology 89:46--55. 
Liedtke, M. 1994. Insurance won't cover most damage: $60 \%$ of homes not covered for quakes. Contra Costa Times, 19 January, 9A.

McNutt, S. R., and Sydnor, R. H. 1990. The Lorna Prieta (Santa Cruz Mountains), California earthquake of 17 October 1989. Special Publication 104. Sacramento: California Department of Conservation, Division of Mines and Geology.

Markus, H., and Kitayama, S. 1991. Culture and the self: Implications for cognition, emotion, and motivation. Psychological Review 98:224-53.

- - - 1992. The what, why and how of cultural psychology: A review of R. Shweder's Thinking through cultures. Psychological Inquiry 3:357-64.

Mattingly, S. 1987. Response and recovery planning with consideration of the scenario: Earthquakes developed by California Division of Mines and Geology. In Proceedings of Conference 41: A review of earthquake research applications in the National Earthquake Hazards Reduction Program: 1977-1987, 550-54. Open File Report 88-13A. Reston, Va.: U.S. Geological Survey.

Mileti, D. S., and Fitzpatrick, C. 1993. The great earthquake experiment: Risk communication and publication. Boulder, Colo.: Westview Press.

Mosteller, F., and Nogee, P. 1941. An experimental measurement of utility. Journal of Political Economy 59:371-404.

Murr, A. 1994. California screaming. Newsweek, 7 February, 19.

National Research Council. 1976. Predicting earthquakes: A scientific and technical evaluation with implications for society. Washington, D.C.: National Academy Press.

Palm, R. 1995. Earthquake insurance: A longitudinal study of California homeowners. Boulder, Colo.: Westview Press.

Palm, R., and Hodgson, M. 1992. After a California earthquake: Attitude and behavior change. Chicago: University of Chicago Press.

- - - 1993. Natural hazards in Puerto Rico: Attitude, experience and behavior of homeowners. Monograph No. 55. Boulder: University of Colorado, Natural Hazards Applications and Information Center.

Palm, R.; Hodgson, M.; Blanchard, D.; and Lyons, D. 1990. Earthquake insurance in California: Environmental policy and individual decision-making. Boulder, Colo.: Westview Press.

Perloff, LS. 1983. Perceptions of vulnerability to victimization. Journal of Social Issues 39:4161.

Perry, R. W.; Greene, M.; and Mushkatel, A. 1986. Minority citizens in disasters. Athens: University of Georgia Press.

Roder, W. 1961. Attitudes and knowledge on the Topeka flood plain. In Papers on flood problems, ed. G. F. White. Research Paper No. 70. Chicago: University of Chicago, Department of Geography.

Roth, R. 1990. The new California Residential Earthquake Recovery Fund and the need for a federal earthquake recovery program. In Hearings before the Subcommittee on Policy Research and Insurance of the Committee on Banking, Finance and Urban Affairs, House of Representatives, Serial No. 101-168, 830-836. Washington, D.C.: Government Printing Office.

Saarinen, T. F. 1982. Environmental planning: Perception and behavior. Boston: Houghton Mifflin

Schiff, M. 1977. Hazard adjustment, locus of control, and sensation seeking: Some null 
findings. Environment and Behavior 9(6): 233-54.

Schkade, D. A., and Johnson, E. J. 1989. Cognitive processes in preference reversals. Organizational Behavior and Human Decision Processes 44:203-31.

Shweder, R. A. 1991. Cultural psychology: Thinking through cultures. Cambridge: Harvard University Press.

Shweder, R. A., and LeVine, R. A. 1984. Culture theory: Essays on mind, self, and emotion. New York: Cambridge University Press.

Slovic, P.; Fischhoff, B.; and Lichtenstein, S.1980. Facts and fears: Understanding perceived risk. In Societal risk assessment: How safe is safe enough?, ed. R. C. Schwing and W. A. Albers, Jr., 181-214. New York: Plenum Press.

Slovic, P.; Fischhoff, B.; Lichtenstein, S.; Corrigan, B.; and Combs, B. 1977. Preference for insuring against probable small losses: Insurance implications. Journal of Risk and Insurance 44:237-58.

Slovic, P.; Kunreuther, H.; and White, G. F. 1974. Decision processes, rationality and adjustment to natural hazards. In Natural hazards: local, national and global, ed. G. F. White, 187-205. New York: Oxford University Press.

Stewart Economics. 1989. The economic impact of a major earthquake. In Catastrophic earthquakes: The need to insure against economic disaster, App. D. Boston: National Committee on Property Insurance.

Stigler, J. W.; Shweder, R. A.; and Herdt, G., eds. 1991. Cultural psychology: Essays on comparative human development. London: Cambridge University Press.

Thier, H. D. 1988. The California earthquake education program. In Proceedings of conference 41: A review of earthquake research applications in the National Earthquake Hazards Reduction Program: 1977-1987, ed. W. W. Hays, 65-74. Open File Report 88-13-A. Reston, Va.: U.S. Geological Survey.

Turner, R.; Nigg, J.; and Paz, D. H. 1986. Waiting for disaster: Earthquake watch in California. Berkeley and Los Angeles: University of California Press.

Turner, R.; Nigg, J.; Paz, D.; and Young, B. 1979. Earthquake threat: The human response in Southern California. Los Angeles: Institute for Social Science Research, University of California.

- - - 1981. Community response to earthquake threat in Southern California. Part 10, summary and recommendations. Los Angeles: Institute for Social Science Research, University of California.

Tversky, A., and Kahneman, D. 1974. Judgment under uncertainty: Heuristics and biases. Science 185:1124-31.

Van Biema, D. 1994. Los Angeles: Tales of the city. Time, 31 January, 40.

Weinstein, N. D. 1987. Unrealistic optimism about illness susceptibility: Conclusions from a community-wide sample. Journal of Behavioral Medicine 10:481-500.

- - - 1989. Effects of personal experience on self-protective behavior. Psychological Bulletin 105:31-50.

White, G. F., and Haas, J. E. 1975. Assessment of research on natural hazards. Cambridge: MIT Press.

Willinger, M. 1989. Risk aversion and the value of information. Journal of Risk and Insurance 56:320-28.

\footnotetext{
${ }^{\mathrm{i}}$ The Roepke Lecture in Economic Geography was established to honor the late Professor Howard G. Roepke, who served on the faculty of the University of Illinois at Urbana- Champaign from 1952 until1985. The lecturer is chosen by the geography faculty of that institution
} 
in consultation with the editors of this journal. The paper was read at the Annual Meeting of the Association of American Geographers, San Francisco, 1994. The research reported here was supported by the National Science Foundation under grants No. BCS-8802896, BCS-8943381, BCS-9017369, BCS-9003573, and BCS-9200681. Opinions, findings, conclusions, or recommendations ex- pressed in this material are those of the author and do not necessarily reflect the views of the National Science Foundation. The author wishes to thank research assistants R. Denise Blanchard, Tom Kochevar, Donald Lyons, and John Carroll, as well as faculty collaborators Michael Hodgson, Jose Molinelli, and Nancy Villanueva, who participated in various portions of these re- search projects. The continued support of NSF program manager William Anderson is deeply appreciated. 